\title{
Review Article \\ Bcl2 Family Functions as Signaling Target in Nicotine-/NNK-Induced Survival of Human Lung Cancer Cells
}

\author{
Xingming Deng \\ Division of Cancer Biology, Department of Radiation Oncology, Emory University School of Medicine and \\ Winship Cancer Institute of Emory University, Atlanta, GA 30322, USA \\ Correspondence should be addressed to Xingming Deng; xdeng4@emory.edu
}

Received 3 March 2014; Accepted 7 May 2014; Published 20 May 2014

Academic Editor: Patrick Auberger

Copyright (C) 2014 Xingming Deng. This is an open access article distributed under the Creative Commons Attribution License, which permits unrestricted use, distribution, and reproduction in any medium, provided the original work is properly cited.

Lung cancer is the leading cause of cancer death and has a strong etiological association with cigarette smoking. Nicotine and nitrosamine 4-(methylnitrosamino)-1-(3-pyridyl)-1-butanone (NNK) are two major components in cigarette smoke that significantly contribute to the development of human lung cancer. Nicotine is able to stimulate survival of both normal human lung epithelial and lung cancer cells. In contrast to nicotine, NNK is a more potent carcinogen that not only induces single-strand DNA breaks and oxidative DNA damage but also stimulates survival and proliferation of normal lung epithelial and lung cancer cells. However, the molecular mechanism(s) by which nicotine and NNK promote cell survival, proliferation, and lung tumor development remains elusive. The fate of cells (i.e., survival or death) is largely decided by the Bcl2 family members. In the past several years, multiple signaling links between nicotine/NNK and $\mathrm{Bcl} 2$ family members have been identified that regulate survival and proliferation. This review provides a concise, systematic overview of the current understanding of the role of the pro- or antiapoptotic proteins in cigarette smoking, lung cancer development, and treatment resistance.

\section{Introduction}

The best currently available therapies for lung cancer patients achieve overall 5-year survival rates of $16 \%$ and $6 \%$ for NSCLC and SCLC, respectively [1]. It has been demonstrated that lung cancer has a strong etiological association with cigarette smoking $[2,3]$. Nicotine and nitrosamine 4-(methylnitrosamino)-1-(3-pyridyl)-1-butanone (NNK) are two important components in cigarette smoke [4]. Recent reports indicate that nicotine promotes survival of both normal human lung epithelial and lung cancer cells $[5,6]$. In contrast to nicotine, NNK is a more potent carcinogen that not only induces single-strand DNA breaks and oxidative DNA damage but also stimulates survival and proliferation of normal lung epithelial and lung cancer cells [6-8]. However, the molecular mechanism(s) by which nicotine and NNK promote cell survival, proliferation, and lung tumor development remains elusive. The fate of cells (i.e., survival or death) is largely decided by the Bcl2 family members $[9,10]$. The subfamily members including Bcl2, Bcl-XL, and Mcl-1 inhibit apoptosis, whereas the Bax subfamily, consisting of
Bax and Bak, as well as the BH3-only subfamily, including Bad, Bid, Bok, Bik, and Bim, promotes apoptosis [11-16]. The Bcl2 family members have homology clustered within four conserved $\mathrm{Bcl} 2$ homology (BH) domains: $\mathrm{BH} 1, \mathrm{BH} 2, \mathrm{BH}$, and $\mathrm{BH} 4$, in which only antiapoptotic proteins, such as $\mathrm{Bcl} 2$, Bcl-XL, Bcl-w, and Al, bear the $\mathrm{NH}_{2}$-terminal $\mathrm{BH} 4$ domain [17]. In contrast, Mcl-1 has a helical BH4-like domain which is located between the PEST region and the $\mathrm{BH} 3$ domain [18]. The proapoptotic family members can be divided into two subgroups based on the presence of $\mathrm{BH}$ domains: the BH123 multidomain proteins (i.e., Bax and Bak) and the BH3only molecules [19-21]. Recent studies suggest that there are two different subgroups among the BH3-only members. One group, including Bid and Bim, can function both directly to bind and activate Bax and indirectly to counteract the inhibition of Bax or Bak by antiapoptotic members including $\mathrm{Bcl} 2$ and Bcl-XL. Other BH3-only proteins (i.e., Bad, Bik, Noxa, and PUMA) lack the ability to directly activate Bax but can oppose the action of antiapoptotic family members. Bcl2 and related antiapoptotic proteins block the progression of a death signal by preventing Bax/Bak oligomerization [22]. 
Importantly, we have recently discovered that the cigarette smoke components, nicotine and NNK, can induce phosphorylation of Bcl2, Mcl-1, Bax, and Bad, which leads to activation of $\mathrm{Bcl} 2$ and $\mathrm{Mcl}-1[5,23]$ and inactivation of Bax and $\mathrm{Bad}$ in association with increased chemoresistance in human lung cancer cells $[24,25]$. Additionally, NNK simultaneously induces both $\mathrm{Bcl} 2$ phosphorylation and $\mathrm{c}-\mathrm{Myc}$ phosphorylation, which promote functional cooperation of these two oncogenic proteins in lung cancer development.

\section{Discussion}

2.1. Cigarette Smoking and Human Lung Cancer. Cigarette smoking is by far the most important risk factor in the development of lung cancer [26]. Cigarette smokers have a 20-fold higher relative risk of developing lung cancer compared with nonsmokers, and 90\% of all lung cancers are caused by smoking [27]. In the United States, cigarette smoking alone causes approximately $30 \%$ of cancer deaths and a total of 440,000 premature deaths annually, most from lung and other cancers. An estimated amount of \$157 billion in annual health-related economic losses is contributable to smoking [28].

2.2. Nicotine, a Major Component in Tobacco, Activates Both Survival and Growth-Promoting Pathways to Facilitate the Development of Lung Cancer. Cigarette smoke contains about 4,000 chemicals, 55 of which have been evaluated as carcinogens [29]. Nicotine is a major component in tobacco that exists at high concentrations $(90-1000 \mathrm{nM})$ in the blood of smokers [30]. High affinity nicotinic acetylcholine receptors (nAChRs) are found on human lung cancer and normal lung cells $[31,32]$. Nicotine functions as a survival agonist to inhibit apoptosis induced by diverse stimuli including chemotherapeutic drugs [33]. However, the intracellular signal transduction mechanism(s) involved in nicotine suppression of apoptosis in human lung cancer cells remains enigmatic. Nicotine has been reported to activate a protein kinase cascade (i.e., $\mathrm{PKC/Raf/MEK/ERKs)} \mathrm{that} \mathrm{may} \mathrm{potentially} \mathrm{promote} \mathrm{survival}$ and proliferation of human lung cancer cells [32-36]. It is interesting to identify the downstream survival and proliferative substrates of nicotine-activated protein kinases. ERK1 and ERK2 have been identified as physiological Bcl2 kinases [37], suggesting that nicotine should have the capacity to regulate $\mathrm{Bcl} 2$ to support survival and potentially promote lung cancer development.

2.3. Bcl2 Is a Potent Antiapoptotic Molecule and Its Phosphorylation in the Flexible Loop Domain Regulates Its Survival Function. The apoptotic process can be divided into three interdependent phases: induction, decision, and execution. The decision phase is largely regulated by the $\mathrm{Bcl} 2$ family of apoptotic regulators $[10,38]$. Bcl 2 can suppress cell death induced by a variety of stress applications including growth factor withdrawal, chemotherapy, irradiation, and viral infection $[10,38]$. However, it is still not clear how Bcl2 actually functions to block apoptosis and promote survival. $\mathrm{Bcl} 2$ was initially identified as a potential phosphoprotein when expressed in SF9 insect cells where it was shown to prolong cell survival following baculovirus infection [39]. Recent reports indicate that the endogenous $\mathrm{Bcl} 2$ expressed in various cells can be phosphorylated and that phosphorylation of $\mathrm{Bcl} 2$ is closely associated with regulation of apoptosis $[37,40,41]$. We have discovered that phosphorylation of $\mathrm{Bcl} 2$ at $\mathrm{S} 70$ in the flexible loop domain (FLD) can positively regulate its antiapoptotic function [37, 42]. Since the nonphosphorylatable S70A Bcl2 mutant results in a significant loss of antiapoptotic function following various stresses, this indicates a survival role for the charge conferred by this posttranslational modification [42]. However, some residual antiapoptotic activities are associated with the S70A mutant $[10,37]$, suggesting that phosphorylation at other sites present in the FLD may also contribute to Bcl2's function. Indeed, $\mathrm{Bcl} 2$ can be phosphorylated at multiple sites in the FLD, including T69, S70, and S87, in association with inhibition of microtubule dynamics [41]. Importantly, conversion of S70 to glutamate (S70E), a charged amino acid that could potentially mimic phosphorylation at S70, resulted in increased cell survival [42]. These data strongly suggest that S70 is a regulatory site for $\mathrm{Bcl} 2$ and allowed us to conclude that phosphorylation at this site may be necessary for Bcl2's survival function $[5,42]$.

2.4. Multiple Protein Kinases Are Involved in Bcl2 Phosphorylation and Regulate Its Antiapoptotic Function. Bryostatin-1, a potent $\mathrm{PKC}$ activator, can induce $\mathrm{Bcl} 2$ phosphorylation at $\mathrm{S} 70$ $[40,42]$, suggesting that PKC appears to be a logical choice as a physiological $\mathrm{Bcl} 2$ kinase. We found that highly purified, activated $\mathrm{PKC} \alpha$ directly phosphorylated $\mathrm{Bcl} 2$ exclusively at S70 in vitro [43]. Furthermore, PKC $\alpha$ could be induced to translocate to the mitochondrial fraction following bryostatin addition to human pre-B REH leukemia-derived cells [43]. Overexpression of PKC $\alpha$ leads to increased $\mathrm{Bcl} 2$ phosphorylation and increased resistance to chemotherapy in $\mathrm{REH}$ cells [43]. These findings suggest that PKC $\alpha$ is a physiological $\mathrm{Bcl} 2$ kinase. However, high concentrations of staurosporine, up to $1 \mu \mathrm{M}$, only partially inhibit IL-3 stimulated Bcl 2 phosphorylation but completely block PKC-mediated Bcl 2 phosphorylation in vitro [37], indicating a role for a staurosporineresistant $\mathrm{Bcl} 2$ kinase (SRK). We have identified that ERK1/2 functions as a physiologic SRK that is able to induce $\mathrm{Bcl} 2$ phosphorylation at S70 in vitro and in vivo [37]. As potential factors in lung cancer development, nicotine and NNK can activate both PKC and SRK (i.e., ERK1/2) physiological $\mathrm{Bcl} 2$ kinases $[5,37,44]$ and inhibit chemotherapeutic druginduced apoptosis in lung cancer cells $[5,29]$. It is possible that nicotine- or NNK-induced inhibition of apoptosis may occur through phosphorylation of $\mathrm{Bcl} 2$.

2.5. Nicotine Induces Bcl2 Phosphorylation at S70 via Activation of $P K C \alpha$ and the ERK1/2 Protein Kinases, Leading to Enhanced Survival of Lung Cancer Cells. Nicotine is a survival agonist that inhibits apoptosis following various stresses [33], but the intracellular signal mechanism(s) that mediates this function remains unclear. $\mathrm{Bcl} 2$ is a cellular protooncogene that functions as a potent antiapoptotic molecule and tumor 
promoter [45]. High levels of Bcl2 are expressed in human lung cancer cells, while the level appears to be low in normal lung cells [46]. A report indicates a correlation between heavy cigarette smoking and increased expression of $\mathrm{Bcl} 2$ in patients with lung, head, and neck cancers, suggesting that $\mathrm{Bcl} 2$ may be a primary target of carcinogens in tobacco smoke [46]. In support of this, we found that high levels of endogenous Bcl2 are expressed in several lung cancer cell lines, including those from SCLC and NSCLC $[47,48]$. Importantly, nicotine can stimulate phosphorylation of endogenous Bcl2 in SCLC H69 cells and enhances cell survival following treatment with chemotherapeutic drugs including VP16 and cisplatin [5]. Nicotine-induced Bcl2 phosphorylation occurs exclusively at the S70 site in association with prolonged survival of SCLC H82 cells expressing wild-type but not the phosphorylationdeficient S70A mutant Bcl2 after treatment with chemotherapeutic agents (i.e., cisplatin or VP-16) [5]. Importantly, nicotine induces $\mathrm{Bcl} 2$ phosphorylation through signaling pathways involving activation of PKC $\alpha$ and the MAPKs ERK1 and ERK2 in lung cancer cells. Since ET-18-OCH3, a specific phospholipase C (PLC) inhibitor, can block nicotinestimulated $\mathrm{Bcl} 2$ phosphorylation and promotes apoptosis [5], it has been proposed that nicotine induces PLC activation that triggers the PKC/ERK1/2 kinase cascade to phosphorylate survival substrate and $\mathrm{Bcl} 2$ and promote cell survival [5]. Nicotine-induced cell survival results, at least in part, from a mechanism that involves Bcl2 phosphorylation at S70 [5]. Therefore, novel therapeutic strategies for lung cancer in which Bcl2 is expressed may be used to abrogate the antiapoptotic activity of $\mathrm{Bcl} 2$ by inhibiting multiple upstream nicotine-activated pathways.

2.6. Nicotine Induces Mcl-1 Phosphorylation in Association with Increased Survival of Human Lung Cancer Cells. Mcl-1 is a major antiapoptotic member of the $\mathrm{Bcl} 2$ family, which is extensively expressed in various human lung cancer cells $[23,49]$. Mcl-1 is a unique member of the Bcl2 family because of its short half-life (30 minutes-3 hours in various cell types) and short-term prosurvival function, which probably relates to the presence of a long proline-, glutamic acid-, serine-, and threonine-rich (PEST) region upstream of the $\mathrm{BH}$ domain [50-53]. Thus, the mechanism(s) that prolongs the half-life of Mcl-1 protein is critical for its long-term survival function. Mcl-1 protein can be phosphorylated at multiple sites that distinctly regulate its protein turnover. For example, extracellular signal-regulated kinase (ERK)1/2mediated phosphorylation at the Thr163 site enhances the half-life and antiapoptotic function of Mcl-1 [54, 55]. In contrast, S159 phosphorylation by GSK-3 $\beta$ facilitates Mcl-1 ubiquitination and degradation to reduce its survival activity [55]. Additionally, Cdk1/2-mediated phosphorylation at the S64 site increases the antiapoptotic function of Mcl-1 but has no effect on its half-life [50]. We recently discovered that nicotine promotes survival of human lung cancer cells through a novel mechanism by activating the antiapoptotic function of Mcl-1 via its phosphorylation [23].
Nicotine activates ERK1/2 through the upstream $\beta$ adrenergic receptor [56], which can induce Mcl-1 phosphorylation at the Thr163 site in the PEST region [23]. Nicotineinduced Mcl-1 phosphorylation at Thr163 enhances the halflife of Mcl-1, which leads to its long-term survival function and/or chemoresistance of human lung cancer cells [23]. Thus, disruption of the antiapoptotic function of Mcl-1 by blocking its Thr163 site phosphorylation may represent a new strategy for the treatment of tobacco-related cancer, especially for lung cancer and other malignancies that express Mcl-1.

2.7. Nicotine and NNK Inactivate the Proapoptotic Function of Bad through Phosphorylation. Bad is one of the BH3only proapoptotic members, and phosphorylation of Bad at $S^{112}, S^{136}$, and $S^{155}$ has been demonstrated to inactivate its proapoptotic function in a mechanism involving binding to 14-3-3 scaffold proteins which results in sequestration of Bad from mitochondria and dissociation of Bad from mitochondrial $\mathrm{Bcl} 2$ and/or $\mathrm{Bcl}-\mathrm{X}_{L}$ [57-60]. The active $\mathrm{Bad}$ is a dephosphorylated form that localizes in the mitochondria and interacts with $\mathrm{Bcl}-\mathrm{X}_{L}$ to neutralize its antiapoptotic function. ERKs, AKT, and PKA function as $B a d S^{112}, S^{136}$, and $S^{155}$ kinases, respectively [61-64]. Nicotine has previously been demonstrated to potently activate both MAPKs ERK1/2 and AKT in association with increased survival of normal lung airway epithelial cells [6]. We discovered that nicotine potently induces Bad phosphorylation at $S^{112}, S^{136}$, and $S^{155}$ in a mechanism involving activation of MAPKs ERK1/2, PI3 K/AKT, and PKA in human lung cancer cells [25]. Nicotine-induced multisite phosphorylation of Bad results in its sequestration from mitochondria and subsequent interaction with 14-3-3 in the cytosol. Interestingly, phosphorylation of Bad at $S^{112}$ occurs earlier than at $S^{136}$ or $S^{155}$, suggesting that nicotine-induced multisite Bad phosphorylation may occur in a hierarchical manner [25]. Phosphorylation of $S^{112}$ may facilitate further phosphorylation of Bad at $S^{136}$ and $S^{155}$ sites. Additionally, NNK has been found to stimulate multisite Bad phosphorylation at $S^{112}, S^{136}$, and $S^{155}$ via activation of $\mathrm{PKC} \iota$ in association with increased survival of human lung cancer cells [65]. Thus, in addition to $\mathrm{Bcl} 2$ and Mcl1, nicotine- or NNK-induced survival may occur, at least in part through inactivation of the BH3-only molecule Bad by phosphorylation, which may contribute to the development of human lung cancer and/or chemoresistance.

2.8. Nicotine Negatively Regulates the Proapoptotic Function of Bax. Bax is a major proapoptotic protein whose activation is required for apoptotic cell death [66]. It has been reported that GM-CSF induces Bax phosphorylation at S184 in the hydrophobic C-terminal tail and inactivates the proapoptotic activity of Bax in neutrophils [67]. These findings reveal that the proapoptotic activity of Bax could be regulated by a posttranslational modification (i.e., phosphorylation). Because Bax is ubiquitously expressed in both SCLC and NSCLC cells, nicotine may mimic growth factor(s) to regulate the activity of Bax. As expected, nicotine has been found to induce Bax phosphorylation at S184, which results in abrogation of 
the proapoptotic activity of Bax and increased cell survival [24]. AKT, a known physiological Bax kinase, is activated by nicotine, colocalizes with Bax in the cytoplasm, and can directly phosphorylate Bax in vitro. Importantly, nicotineinduced Bax phosphorylation potently blocks stress-induced translocation of Bax from the cytosol to the mitochondria, impairs Bax insertion into mitochondrial membranes, and reduces the half-life of Bax protein [24]. Additionally, we identified $\mathrm{PKC} \zeta$ as another nicotine-activated Bax kinase that is able to directly phosphorylate Bax in human lung cancer cells [68]. Therefore, nicotine-induced survival and chemoresistance of human lung cancer cells may occur through a mechanism involving activation of PI3 K/AKT and $\mathrm{PKC} \zeta$ that directly phosphorylates Bax leading to inactivation of its proapoptotic function, which may contribute to the development and/or chemoresistance of human lung cancer.

2.9. NNK Promotes Functional Cooperation of Bcl2 and cMyc through Phosphorylation in Human Lung Cancer Cells. Among the known protooncogenes, the cellular myc gene (c$\mathrm{Myc}$ ) is one of those most frequently implicated in carcinogenesis $[69,70]$. Deregulated expression of the structurally unaltered Myc protein is sufficient to drive continuous cell proliferation and apoptosis in response to growth-promoting and growth-inhibitory signals, respectively [69]. Expression of the oncogene c-Myc can initiate proliferation and increase sensitivity to apoptosis under low serum conditions when antiapoptotic mechanisms are not activated [71]. Activation of the Raf/MEK/ERK and the PI3-K/AKT kinase cascades regulates the phosphorylation of two sites (i.e., Thr58 and $\mathrm{S} 62$ ) in the $\mathrm{N}$ terminus of $\mathrm{c}-\mathrm{Myc}$, which are conserved between all Myc family members and have opposing effects on Myc stability [72]. Since nicotine and NNK have been reported to induce activation of both the Raf/MEK/ERK and the PI3-K/AKT kinase cascades $[6,7,44]$, these two distinct pathways may cooperate to regulate the stability of c-Myc through phosphorylation of S62 and Thr58. Bcl2 and c-Myc are two major oncogenic proteins that can functionally cooperate in cell proliferation, transformation, apoptosis, and tumorigenicity [73]. To avoid c-Myc-induced cell death and ensure continuous cell proliferation, $\mathrm{Bcl} 2$ functions as one of the most potent Myc-cooperating oncoproteins [74, 75], which is a global inhibitor of apoptosis, likelythrough multiple mechanisms $[37,69]$. Bcl 2 can specifically abrogate c-Myc-induced apoptosis without affecting the c-Myc mitogenic function [74]. Interestingly, NNK can simultaneously stimulate $\mathrm{Bcl} 2$ phosphorylation exclusively at S70 and cMyc phosphorylation at Thr58 and S62 through activation of both ERK1/2 and PKC $\alpha$ [47], which facilitates a functional cooperation between $\mathrm{Bcl} 2$ and $\mathrm{c}-\mathrm{Myc}$ leading to enhanced survival, proliferation, and chemoresistance of human lung cancer cells.

\section{Conclusion}

Cigarette smoking is the most important risk factor in the development of lung cancer. Interestingly, cigarette smoke components (i.e., nicotine and $\mathrm{NNK}$ ) can regulate $\mathrm{Bcl} 2$ family

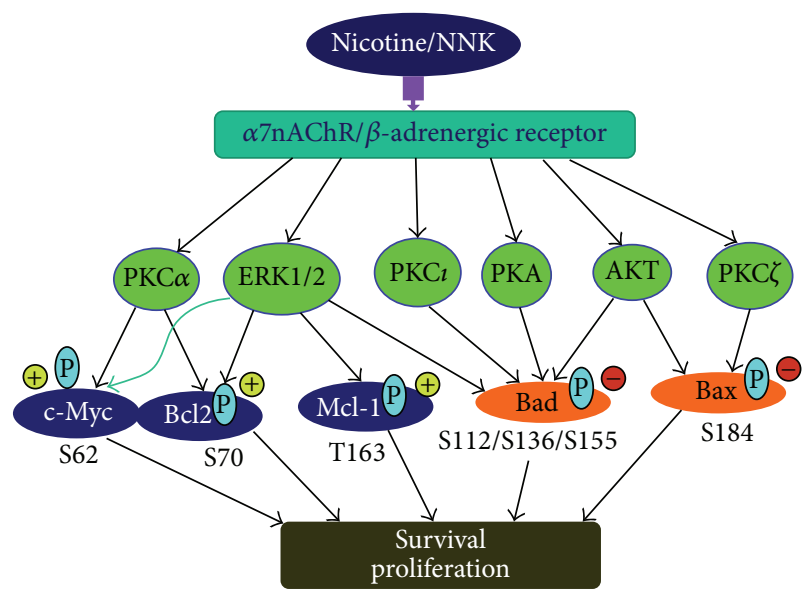

FIGURE 1: Proposed model of nicotine/NNK signaling in human lung cancer cells. Nicotine or NNK stimulates phosphorylation of $\mathrm{Bcl} 2, \mathrm{Mcl}-1, \mathrm{Bad}$, and Bax via activation of multiple protein kinases leading to activation of $\mathrm{Bcl} 2 / \mathrm{Mcl}-1$, inactivation of $\mathrm{Bad} / \mathrm{Bax}$, and promotion of functional cooperation between $\mathrm{Bcl} 2$ and $\mathrm{c}-\mathrm{Myc}$, which contributes to the survival and proliferation of human lung cancer cells.

members through multiple signaling pathways in human lung cancer cells (Figure 1). Nicotine or NNK induces the phosphorylation of $\mathrm{Bcl} 2, \mathrm{Mcl}-1, \mathrm{Bad}$, and Bax through activation of ERK1/2, AKT, PKA, PKC $\alpha, \mathrm{PKC} \iota$, and $\mathrm{PKC} \zeta$. Nicotine/NNK-induced phosphorylation of $\mathrm{Bcl} 2$ and $\mathrm{Mcl}-1$ enhances their antiapoptotic functions, while phosphorylation of Bax and Bad inactivates their proapoptotic functions, which contributes to increased survival and chemoresistance of human lung cancer cells. NNK can stimulate the functional cooperation of $\mathrm{Bcl} 2$ and $\mathrm{c}-\mathrm{Myc}$ via phosphorylation, which may promote lung cancer development. To explore the relevance of the signaling pathways we have characterized, in cell lines for clinical patients, the phosphorylation status of $\mathrm{Bcl} 2, \mathrm{Mcl}-1, \mathrm{Bad}$, or Bax in tumor tissues from smoking and nonsmoking lung cancer patients which should be evaluated in future studies. Thus, our cell-based findings in combination with data from patients will provide strong clinical relevance for prognosis as well as for the treatment of tobacco-related cancers, specifically lung or other $\mathrm{Bcl} 2$ family and c-Myc expressing malignancies. These studies may contribute significantly to the development of novel strategies specifically aimed at functionally blocking multiple $\mathrm{Bcl} 2$ family signaling pathways.

\section{Conflict of Interests}

The author declares that there is no conflict of interests regarding the publication of this paper.

\section{Acknowledgments}

This work was supported by NCI, National Institutes of Health, Grants R01CA112183 and R01CA136534 and by Flight Attendant Medical Research Institute Clinical Innovator 
Award. The author thanks Anthea Hammond for editing the paper.

\section{References}

[1] A. Jemal, R. Siegel, E. Ward, T. Murray, J. Xu, and M. J. Thun, "Cancer statistics, 2007," CA: A Cancer Journal for Clinicians, vol. 57 , no. 1, pp. 43-66, 2007.

[2] H. M. Schuller, P. K. Tithof, M. Williams, and H. Plummer 3rd, "The tobacco-specific carcinogen 4-(methylnitrosamino)1-(3-pyridyl)-1-butanone is a beta-adrenergic agonist and stimulates DNA synthesis in lung adenocarcinoma via betaadrenergic receptor-mediated release of arachidonic acid," Cancer Research, vol. 59, no. 18, pp. 4510-4515, 1999.

[3] S. S. Hecht, "Lung carcinogenesis by tobacco smoke," International Journal of Cancer, vol. 131, no. 12, pp. 2724-2732, 2012.

[4] H. M. Schuller, "Mechanisms of smoking-related lung and pancreatic adenocarcinoma development," Nature Reviews Cancer, vol. 2, no. 6, pp. 455-463, 2002.

[5] H. Mai, W. S. May, F. Gao, Z. Jin, and X. Deng, "A functional role for nicotine in $\mathrm{Bcl} 2$ phosphorylation and suppression of apoptosis," Journal of Biological Chemistry, vol. 278, no. 3, pp. 1886-1891, 2003.

[6] K. A. West, J. Brognard, A. S. Clark et al., "Rapid Akt activation by nicotine and a tobacco carcinogen modulates the phenotype of normal human airway epithelial cells," Journal of Clinical Investigation, vol. 111, no. 1, pp. 81-90, 2003.

[7] B. Jull, H. Plummer, and H. Schuller, "Nicotinic receptormediated activation by the tobacco-specific nitrosamine NNK of a Raf-1/MAP kinase pathway, resulting in phosphorylation of c-myc in human small cell lung carcinoma cells and pulmonary neuroendocrine cells," Journal of Cancer Research and Clinical Oncology, vol. 127, no. 12, pp. 707-717, 2001.

[8] R. Jorquera, A. Castonguay, and H. M. Schuller, "DNA singlestrand breaks and toxicity induced by 4-(methylnitrosamino)-1(3-pyridyl)-1-butanone or N-nitrosodimethylamine in hamster and rat liver," Carcinogenesis, vol. 15, no. 2, pp. 389-394, 1994.

[9] A. Gross, J. M. McDonnell, and S. J. Korsmeyer, "BCL-2 family members and the mitochondria in apoptosis," Genes and Development, vol. 13, no. 15, pp. 1899-1911, 1999.

[10] J. M. Adams and S. Cory, "The Bcl-2 protein family: arbiters of cell survival," Science, vol. 281, no. 5381, pp. 1322-1326, 1998.

[11] M. Suzuki, R. J. Youle, and N. Tjandra, "Structure of bax: coregulation of dimer formation and intracellular localization," Cell, vol. 103, no. 4, pp. 645-654, 2000.

[12] S. N. Farrow and R. Brown, "New members of the Bcl-2 family and their protein partners," Current Opinion in Genetics \& Development, vol. 6, no. 1, pp. 45-49, 1996.

[13] Z. N. Oltvai, C. L. Milliman, and S. J. Korsmeyer, "Bcl-2 heterodimerizes in vivo with a conserved homolog, Bax, that accelerates programed cell death," Cell, vol. 74, no. 4, pp. 609619, 1993.

[14] G. Kroemer, "The proto-oncogene Bcl-2 and its role in regulating apoptosis," Nature Medicine, vol. 3, no. 6, pp. 614-620, 1997.

[15] H. Li, H. Zhu, C. Xu, and J. Yuan, "Cleavage of BID by caspase 8 mediates the mitochondrial damage in the Fas pathway of apoptosis," Cell, vol. 94, no. 4, pp. 491-501, 1998.

[16] W. Zong, T. Lindsten, A. J. Ross, G. R. MacGregor, and C. B. Thompson, "BH3-only proteins that bind pro-survival Bcl-2 family members fail to induce apoptosis in the absence of Bax and Bak," Genes and Development, vol. 15, no. 12, pp. 1481-1486, 2001.

[17] A. Kelekar and C. B. Thompson, "Bcl-2-family proteins: the role of the BH3 domain in apoptosis," Trends in Cell Biology, vol. 8, no. 8, pp. 324-330, 1998.

[18] A. De Biasio, J. A. Vrana, P. Zhou et al., "N-terminal truncation of antiapoptotic MCL1, but not G2/M- induced phosphorylation, is associated with stabilization and abundant expression in tumor cells," Journal of Biological Chemistry, vol. 282, no. 33, pp. 23919-23936, 2007.

[19] L. Chen, S. N. Willis, A. Wei et al., "Differential targeting of prosurvival $\mathrm{Bcl}-2$ proteins by their $\mathrm{BH} 3$-only ligands allows complementary apoptotic function," Molecular Cell, vol. 17, no. 3, pp. 393-403, 2005.

[20] T. Kuwana, L. Bouchier-Hayes, J. E. Chipuk et al., "BH3 domains of $\mathrm{BH} 3$-only proteins differentially regulate Bax-mediated mitochondrial membrane permeabilization both directly and indirectly," Molecular Cell, vol. 17, no. 4, pp. 525-535, 2005.

[21] L. J. Pagliari, T. Kuwana, C. Bonzon et al., "The multidomain proapoptotic molecules Bax and Bak are directly activated by heat," Proceedings of the National Academy of Sciences of the United States of America, vol. 102, no. 50, pp. 17975-17980, 2005.

[22] A. Letai, "BCL-2: found bound and drugged!," Trends in Molecular Medicine, vol. 11, no. 10, pp. 442-444, 2005.

[23] J. Zhao, M. Xin, T. Wang, Y. Zhang, and X. Deng, "Nicotine enhances the antiapoptotic function of Mcl-1 through phosphorylation," Molecular Cancer Research, vol. 7, no. 12, pp. 19541961, 2009.

[24] M. Xin and X. Deng, "Nicotine inactivation of the proapoptotic function of Bax through phosphorylation," Journal of Biological Chemistry, vol. 280, no. 11, pp. 10781-10789, 2005.

[25] Z. Jin, F. Gao, T. Flagg, and X. Deng, "Nicotine induces multisite phosphorylation of Bad in association with suppression of apoptosis," Journal of Biological Chemistry, vol. 279, no. 22, pp. 23837-23844, 2004.

[26] S. D. Stellman, T. Takezaki, L. Wang et al., "Smoking and lung cancer risk in American and Japanese men: an international case-control study," Cancer Epidemiology Biomarkers and Prevention, vol. 10, no. 11, pp. 1193-1199, 2001.

[27] C. M. Dresler, "Is it more important to quit smoking than which chemotherapy is used?" Lung Cancer, vol. 39, no. 2, pp. 119-124, 2003.

[28] Centers for Disease Control and Prevention, "Annual smokingattributable mortality, years of potential life lost, and economic costs-United States, 1995-1999," Morbidity and Mortality Weekly Report, vol. 51, no. 14, pp. 300-303, 2002.

[29] S. S. Hecht, "Tobacco smoke carcinogens and lung cancer," Journal of the National Cancer Institute, vol. 91, no. 14, pp. 11941210, 1999.

[30] N. L. Benowitz, "Drug therapy. Pharmacologic aspects of cigarette smoking and nicotine addiction," The New England Journal of Medicine, vol. 319, no. 20, pp. 1318-1330, 1988.

[31] M. F. Denissenko, A. Pao, M. Tang, and G. P. Pfeifer, "Preferential formation of benzo[a]pyrene adducts at lung cancer mutational hotspots in P53," Science, vol. 274, no. 5286, pp. 430432, 1996.

[32] R. Maneckjee and J. D. Minna, "Opioid and nicotine receptors affect growth regulation of human lung cancer cell lines," Proceedings of the National Academy of Sciences of the United States of America, vol. 87, no. 9, pp. 3294-3298, 1990. 
[33] S. C. Wright, J. Zhong, H. Zheng, and J. W. Larrick, "Nicotine inhibition of apoptosis suggests a role in tumor promotion," The FASEB Journal, vol. 7, no. 11, pp. 1045-1051, 1993.

[34] W. L. Heusch and R. Maneckjee, "Signalling pathways involved in nicotine regulation of apoptosis of human lung cancer cells," Carcinogenesis, vol. 19, no. 4, pp. 551-556, 1998.

[35] S. G. Rhee and Y. S. Bae, "Regulation of phosphoinositidespecific phospholipase C isozymes," The Journal of Biological Chemistry, vol. 272, pp. 15045-15048, 1997.

[36] J. Shen, L. Xu, T. K. Owonikoko et al., "NNK promotes migration and invasion of lung cancer cells through activation of cSrc/PKCı/FAK loop," Cancer Letters, vol. 318, no. 1, pp. 106-113, 2012.

[37] X. Deng, P. Ruvolo, B. Carr, and W. S. May Jr., "Survival function of ERK1/2 as IL-3-activated, staurosporine-resistant Bcl2 kinases," Proceedings of the National Academy of Sciences of the United States of America, vol. 97, no. 4, pp. 1578-1583, 2000.

[38] E. Yang and S. J. Korsmeyer, "Molecular thanatopsis: a discourse on the BCL2 family and cell death," Blood, vol. 88, no. 2, pp. 386401, 1996.

[39] E. S. Alnemri, N. M. Robertson, T. F. Fernandes, C. M. Croce, and G. Litwack, "Overexpressed full-length human BCL2 extends the survival of baculovirus- infected Sf9 insect cells," Proceedings of the National Academy of Sciences of the United States of America, vol. 89, no. 16, pp. 7295-7299, 1992.

[40] W. S. May, P. G. Tyler, T. Ito, D. K. Armstrong, K. A. Qatsha, and N. E. Davidson, "Interleukin-3 and bryostatin-1 mediate hyperphosphorylation of $\mathrm{Bcl} 2 \alpha$ in association with suppression of apoptosis," Journal of Biological Chemistry, vol. 269, no. 43, pp. 26865-26870, 1994.

[41] K. Yamamoto, H. Ichijo, and S. J. Korsmeyer, "BCL-2 is phosphorylated and inactivated by an ASK1/Jun N-terminal protein kinase pathway normally activated at G(2)/M," Molecular and Cellular Biology, vol. 19, no. 12, pp. 8469-8478, 1999.

[42] T. Ito, X. Deng, B. Carr, and W. S. May, "Bcl-2 phosphorylation required for anti-apoptosis function," The Journal of Biological Chemistry, vol. 272, pp. 11671-11673, 1997.

[43] P. P. Ruvolo, X. Deng, B. K. Carr, and W. S. May, "A functional role for mitochondrial protein kinase $\mathrm{C} \alpha$ in $\mathrm{Bcl} 2$ phosphorylation and suppression of apoptosis," Journal of Biological Chemistry, vol. 273, no. 39, pp. 25436-25442, 1998.

[44] H. M. Schuller, H. K. Plummer 3rd, and B. A. Jull, "Receptormediated effects of nicotine and its nitrosated derivative NNK on pulmonary neuroendocrine cells," Anatomical Record A: Discoveries in Molecular, Cellular, and Evolutionary Biology, vol. 270, no. 1, pp. 51-58, 2003.

[45] G. P. Linette, J. L. Hess, C. L. Sentman, and S. J. Korsmeyer, "Peripheral T-cell lymphoma in lckpr-bcl-2 transgenic mice," Blood, vol. 86, no. 4, pp. 1255-1260, 1995.

[46] N. Ikegaki, M. Katsumata, J. Minna, and Y. Tsujimoto, "Expression of bcl-2 in small cell lung carcinoma cells," Cancer Research, vol. 54, no. 1, pp. 6-8, 1994.

[47] Z. Jin, F. Gao, T. Flagg, and X. Deng, "Tobacco-specific nitrosamine 4-(methylnitrosamino)-1-(3-pyridyl)-1-butanone promotes functional cooperation of $\mathrm{Bcl} 2$ and c-Myc through phosphorylation in regulating cell survival and proliferation," Journal of Biological Chemistry, vol. 279, no. 38, pp. 4020940219, 2004.

[48] Z. Jin, W. S. May, F. Gao, T. Flagg, and X. Deng, "Bcl2 suppresses DNA repair by enhancing c-Myc transcriptional activity," Journal of Biological Chemistry, vol. 281, no. 20, pp. 14446-14456, 2006.
[49] L. Song, D. Coppola, S. Livingston, D. Cress, and E. B. Haura, "Mcl-1 regulates survival and sensitivity to diverse apoptotic stimuli in human non-small cell lung cancer cells," Cancer Biology and Therapy, vol. 4, no. 3, pp. 267-276, 2005.

[50] S. Kobayashi, S. Lee, X. W. Meng et al., "Serine 64 phosphorylation enhances the antiapoptotic function of Mcl-1," Journal of Biological Chemistry, vol. 282, no. 25, pp. 18407-18417, 2007.

[51] J. Chao, J. M. Wang, S. F. Lee et al., "Mcl-1 is an immediateearly gene activated by the granulocyte-macrophage colonystimulating factor (GM-CSF) signaling pathway and is one component of the GM-CSF viability response," Molecular and Cellular Biology, vol. 18, no. 8, pp. 4883-4898, 1998.

[52] D. Nijhawan, M. Fang, E. Traer et al., "Elimination of Mcl-1 is required for the initiation of apoptosis following ultraviolet irradiation," Genes and Development, vol. 17, no. 12, pp. 14751486, 2003.

[53] H. Liu, H. W. Peng, Y. S. Cheng, H. S. Yuan, and H. F. Yang-Yen, "Stabilization and enhancement of the antiapoptotic activity of Mcl-1 by TCTP," Molecular and Cellular Biology, vol. 25, no. 8, pp. 3117-3126, 2005.

[54] A. M. Domina, J. A. Vrana, M. A. Gregory, S. R. Hann, and R. W. Craig, "MCL1 is phosphorylated in the PEST region and stabilized upon ERK activation in viable cells, and at additional sites with cytotoxic okadaic acid or taxol," Oncogene, vol. 23, no. 31, pp. 5301-5315, 2004.

[55] A. M. Domina, J. H. Smith, and R. W. Craig, "Myeloid cell leukemia 1 is phosphorylated through two distinct pathways, one associated with extracellular signal-regulated kinase activation and the other with $\mathrm{G} 2 / \mathrm{M}$ accumulation or protein phosphatase 1/2A inhibition," Journal of Biological Chemistry, vol. 275, no. 28, pp. 21688-21694, 2000.

[56] V. Y. Shin, W. K. Wu, K. M. Chu et al., "Functional role of $\beta$-adrenergic receptors in the mitogenic action of nicotine on gastric cancer cells," Toxicological Sciences, vol. 96, no. 1, pp. 2129, 2007.

[57] I. Hirai and H.-G. Wang, "Survival-factor-induced phosphorylation of Bad results in its dissociation from Bcl-x(L) but not Bcl-2," Biochemical Journal, vol. 359, no. 2, pp. 345-352, 2001.

[58] Y. Tan, M. R. Demeter, H. Ruan, and M. J. Comb, "BAD Ser155 phosphorylation regulates $\mathrm{BAD} / \mathrm{Bcl}-\mathrm{XL}$ interaction and cell survival," Journal of Biological Chemistry, vol. 275, no. 33, pp. 25865-25869, 2000.

[59] A. Bergmann, "Survival signaling goes BAD," Developmental Cell, vol. 3, no. 5, pp. 607-608, 2002.

[60] S. R. Datta, A. Katsov, L. Hu et al., "14-3-3 proteins and survival kinases cooperate to inactivate $\mathrm{BAD}$ by $\mathrm{BH} 3$ domain phosphorylation," Molecular Cell, vol. 6, no. 1, pp. 41-51, 2000.

[61] M. P. Scheid, K. M. Schubert, and V. Duronio, "Regulation of bad phosphorylation and association with $\mathrm{Bcl}-\mathrm{x}(\mathrm{L})$ by the MAPK/Erk kinase," Journal of Biological Chemistry, vol. 274, no. 43, pp. 31108-31113, 1999.

[62] S. R. Datta, H. Dudek, X. Tao et al., "Akt phosphorylation of BAD couples survival signals to the cell-intrinsic death machinery," Cell, vol. 91, no. 2, pp. 231-241, 1997.

[63] X. M. Zhou, Y. Liu, G. Payne, R. J. Lutz, and T. Chittenden, "Growth factors inactivate the cell death promoter BAD by phosphorylation of its BH3 domain on Ser155," Journal of Biological Chemistry, vol. 275, no. 32, pp. 25046-25051, 2000.

[64] X. Fang, S. Yu, A. Eder et al., "Regulation of BAD phosphorylation at serine 112 by the Ras-mitogen-activated protein kinase pathway," Oncogene, vol. 18, no. 48, pp. 6635-6640, 1999. 
[65] Z. Jin, M. Xin, and X. Deng, "Survival function of protein kinase $\mathrm{C}\{$ iota $\}$ as a novel nitrosamine 4-(methylnitrosamino)-1-(3pyridyl)-1-butanone-activated bad kinase," Journal of Biological Chemistry, vol. 280, no. 16, pp. 16045-16052, 2005.

[66] M. C. Wei, W. X. Zong, E. H. Cheng et al., "Proapoptotic BAX and BAK: a requisite gateway to mitochondrial dysfunction and death," Science, vol. 292, no. 5517, pp. 727-730, 2001.

[67] S. J. Gardai, D. A. Hildeman, S. K. Frankel et al., "Phosphorylation of Bax Ser184 by Akt regulates its activity and apoptosis in neutrophils," Journal of Biological Chemistry, vol. 279, no. 20, pp. 21085-21095, 2004.

[68] M. Xin, F. Gao, W. S. May, T. Flagg, and X. Deng, "Protein kinase Czeta abrogates the proapoptotic function of Bax through phosphorylation," Journal of Biological Chemistry, vol. 282, no. 29, pp. 21268-21277, 2007.

[69] E. L. Soucie, M. G. Annis, J. Sedivy et al., "Myc potentiates apoptosis by stimulating Bax activity at the mitochondria," Molecular and Cellular Biology, vol. 21, no. 14, pp. 4725-4736, 2001.

[70] D. Hanahan and R. A. Weinberg, "The hallmarks of cancer," Cell, vol. 100, no. 1, pp. 57-70, 2000.

[71] G. I. Evan, A. H. Wyllie, C. S. Gilbert et al., "Induction of apoptosis in fibroblasts by c-myc protein," Cell, vol. 69, no. 1, pp. 119128, 1992.

[72] R. Sears, F. Nuckolls, E. Haura, Y. Taya, K. Tamai, and J. R. Nevins, "Multiple Ras-dependent phosphorylation pathways regulate Myc protein stability," Genes and Development, vol. 14, no. 19, pp. 2501-2514, 2000.

[73] J. C. Reed, M. Cuddy, S. Haldar et al., "BCL2-mediated tumorigenicity of a human T-lymphoid cell line: synergy with MYC and inhibiton by BCL2 antisense," Proceedings of the National Academy of Sciences of the United States of America, vol. 87, no. 10, pp. 3660-3664, 1990.

[74] A. Fanidi, E. A. Harrington, and G. I. Evan, "Cooperative interaction between c-myc and bcl-2 proto-oncogenes," Nature, vol. 359, no. 6395, pp. 554-556, 1992.

[75] R. P. Bissonnette, F. Echeverri, A. Mahboubi, and D. R. Green, "Apoptotic cell death induced by c-myc is inhibited by bcl-2," Nature, vol. 359, no. 6395, pp. 552-554, 1992. 

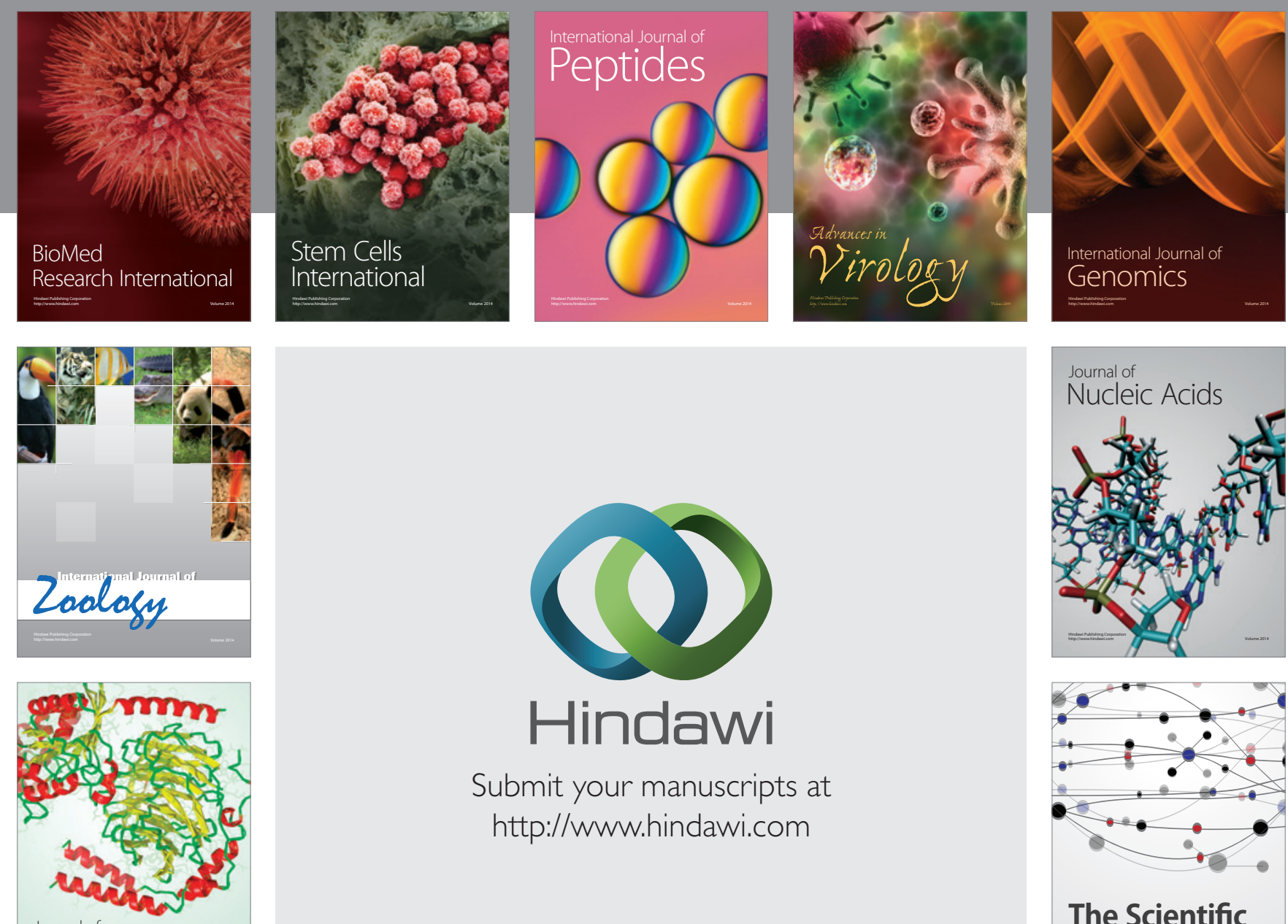

Submit your manuscripts at

http://www.hindawi.com

Journal of
Signal Transduction
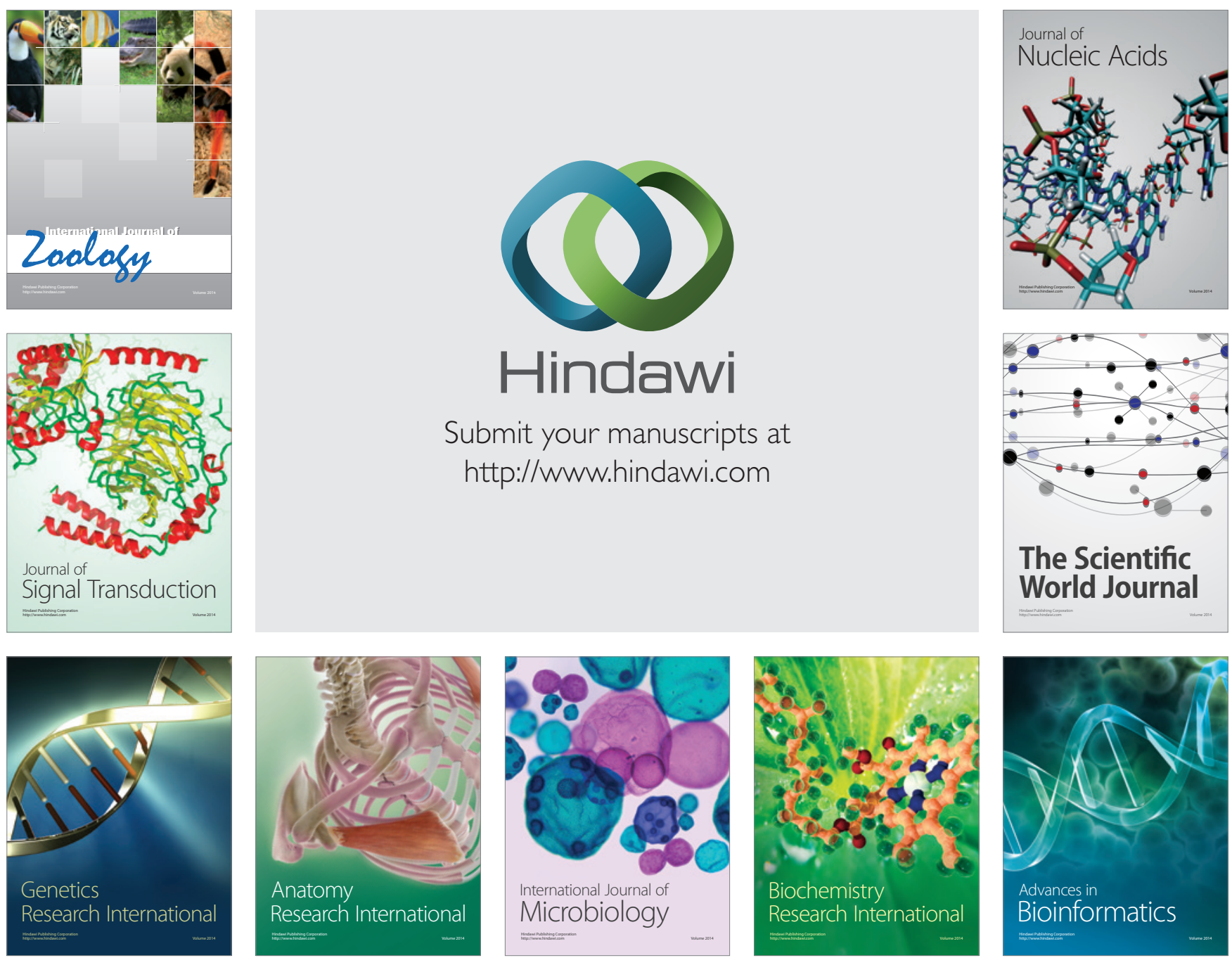

The Scientific World Journal
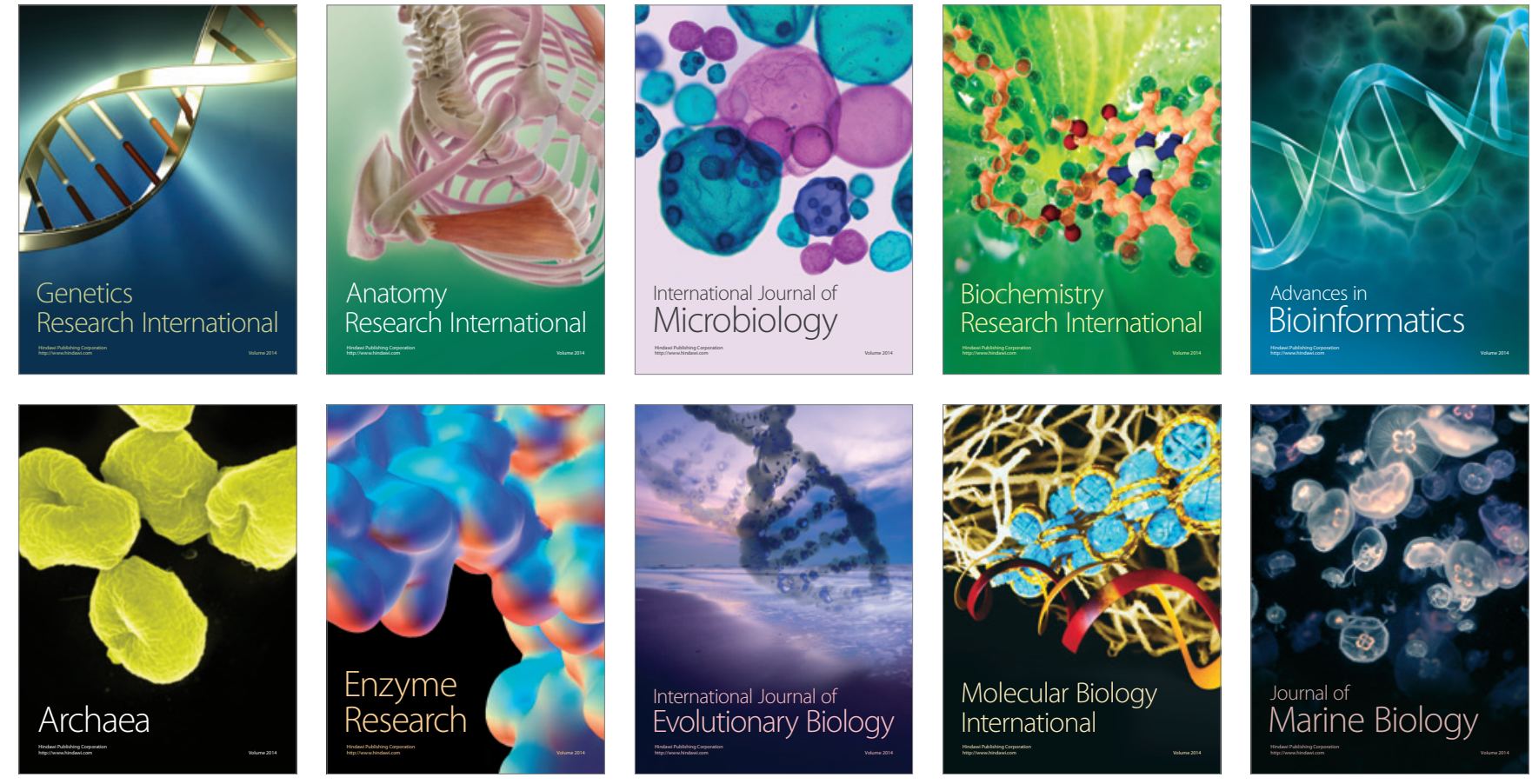